\title{
Seasonal Forecast of Early Summer Rainfall at Stations in South China Using a Statistical Downscaling Model
}

\author{
ZHENG LU \\ State Key Laboratory of Earth Surface Processes and Resource Ecology, Beijing Normal University, Beijing, China \\ YAN GUO \\ State Key Laboratory of Earth Surface Processes and Resource Ecology, Beijing Normal University, Beijing, and \\ Southern Marine Science and Engineering Guangdong Laboratory, Guangzhou, China \\ JIANGSHAN ZHU \\ Institute of Atmospheric Physics, Chinese Academy of Sciences, Beijing, China \\ NING KANG \\ National Satellite Meteorological Centre, Beijing, China
}

(Manuscript received 18 November 2019, in final form 23 May 2020)

\begin{abstract}
Current dynamic models are not able to provide reliable seasonal forecasts of regional/local rainfall. This study aims to improve the seasonal forecast of early summer rainfall at stations in South China through statistical downscaling. A statistical downscaling model was built with the canonical correlation analysis method using 850-hPa zonal wind and relative humidity from the ERA-Interim reanalysis data. An anomalous southwesterly wind that carries sufficient water vapor encounters an anomalous northeasterly wind from the Yangtze River, resulting in a wet anomaly over all of South China. This model provided good agreement with observations in both the training and independent test periods. In an independent test, the average temporal correlation coefficient (TCC) at 14 stations was 0.52 , and the average root-mean-square error was $21 \%$. Then, the statistical downscaling model was applied to the Climate Forecast System, version 2 (CFSv2), outputs to produce seasonal forecasts of rainfall for 1982-2018. A statistical downscaling model improved CFSv2 forecasts of station rainfall in South China with the average TCC increasing from 0.14 to 0.31 . Forecasts of South China regionally averaged rainfall were also improved with the TCC increasing from 0.11 to 0.53 . The dependence of forecast skill for regional average rainfall on ENSO events was examined. Forecast error was reduced, but not statistically significant, when it followed an El Niño event in both CFSv2 and the downscaling model. While when it followed an EP-type El Niño, the significantly reduced forecast error (at the 0.1 level) could be seen in the downscaling model and CFSv2.
\end{abstract}

\section{Introduction}

Seasonal rainfall forecast is of great significance to human survival and societal development. It is in high demand for the agriculture, water resource management, energy, and transportation sectors. South China receives plentiful annual rainfall that has obvious seasonality. The rainy season in South China is characterized by two flood periods: the early summer flood period (April-June), with mainly frontal rainfall (Chang et al. 2006; Chi et al. 2005; Zheng et al. 2006), and the

Corresponding author: Dr. Yan Guo,guoyan@bnu.edu.cn. late-summer flood period, with mainly convective rainfall (Ding and Liang 2002). South China early summer rainfall is attributed to large-scale synoptic rainfall, and long-lasting heavy rainfall events that cause severe social impacts often occur in this period. Spatially, early summer rainfall is notably uneven, with more rainfall in the southeastern area and less rainfall in the northeastern area (Hui et al. 2006). South China early summer rainfall is characterized by strong interannual variability; in some years, it is extremely abundant, causing flood disasters, while in some other years, it is extremely scarce, resulting in severe droughts. Hui et al. (2006) reported that the interannual variability 
has significantly increased over the past 50 years, which implies the occurrence of more floods and droughts than ever before. Therefore, providing a reliable seasonal forecast of early summer rainfall in South China is an important issue that is relevant to disaster prevention and mitigation.

Previous studies indicated that interannual variation of South China early summer rainfall is highly associated with large-scale circulation anomalies, such as the northern cold-air injection (Chi et al. 2005), the South Asia high (Ma et al. 2009), and the western North Pacific subtropical high (Chi et al. 2005; Ma et al. 2009; Zheng et al. 2006). It is also affected by larger-scale sea surface temperature (SST) anomalies, such as El Niño-Southern Oscillation (ENSO) (Gong and Wang 1999; Lu et al. 2002) and the Indian Ocean dipole (IOD) (Deng and Wang 2002; Hu et al. 2017; Hui et al. 2009), which are sources of predictability for South China early summer rainfall.

Currently, seasonal forecasts with fully coupled climate models are made routinely in a number of weather and climate centers worldwide due to advances both in understanding the physical mechanisms of climate and in computing capability (Kanamitsu et al. 2002; Palmer et al. 2004). However, seasonal forecasting abilities vary by variable and location. At present, rainfall forecasts remain at a low level, especially in the East Asian summer monsoon domain (Guo et al. 2014; Lee et al. 2011; Wu et al. 2009). The ability to forecast local (station-scale) rainfall is even low. Currently, statistical postprocessing based on dynamic model forecasts is a feasible way to achieve satisfactory forecasts of local rainfall.

Statistical downscaling is a useful technique for estimating local climate that links with large-scale climate anomalies (predictors) by developing a robust statistical relationship (Benestad 2004; Fowler et al. 2007) with reanalysis data [perfect prognosis (PP)] or directly with model outputs [model output statistics (MOS)]. Compared with that of MOS, the statistical relationship established using PP is more physically meaningful. Thus, $\mathrm{PP}$ is chosen for use in this study. For the statistical downscaling method, transfer functions, which mainly consist of multilinear regression (MLR), singular value decomposition (SVD), and canonical correlation analysis (CCA), are suitable for seasonal forecasting.

A number of previous studies have demonstrated that statistical downscaling models generally perform well in forecasting seasonal rainfall in China (Guo et al. 2014; Liu and Fan 2014; Ruan et al. 2015). Liu et al. (2011) developed a statistical downscaling model with the MLR method to forecast summer rainfall at stations in South China. In contrast to the MLR equation established at each station in Liu et al. (2011), the pattern-based SVD method is preferred because it can reveal the connections between large-scale predictors and local predictands. Liu et al. (2013) statistically downscaled summer rainfall at stations in China with the SVD method based on 500-hPa geopotential height $H_{500}$ and SST from the Climate Forecast System, version 2 (CFSv2), and its spatial correlation coefficient reached 0.31. Tung et al. (2013) also used the SVD method to develop a statistical downscaling model to improve the station summer rainfall forecast in South China. Yan et al. (2004) indicated that CCA is superior to SVD because it can distill the correlativity of two fields more effectively, and the coordinate systems obtained from CCA, which are orthogonal, could optimally describe the cross covariance between predictors and predictands. However, in some cases, when the variable number is greater than the sample size, the estimation of the inverse matrices in CCA is impossible. A method BP-CCA was proposed (Barnett and Preisendorfer 1987) in which the empirical orthogonal function (EOF) is first performed and then CCA is performed on the principal components (PCs). BP-CCA was applied for the statistical downscaling of station rainfall in China and showed good performance (Chen et al. 2017; Jia et al. 2010).

In this study, we aim to improve the seasonal forecasts of early summer rainfall at stations in South China through statistical downscaling with a BP-CCA method and apply the downscaling model to dynamic model outputs to produce seasonal forecasts. The remainder of this paper is structured as follows: section 2 presents the observational/reanalysis data and the dynamic model data. Section 3 describes the statistical downscaling scheme in detail. In section 4, statistical downscaling model is built, validated, and applied to dynamic model outputs to produce seasonal forecast. Finally, section 5 is devoted to a brief summary and discussion.

\section{Data}

Observational rainfall data were extracted from China's 160 station monthly rainfall dataset provided by the China Meteorological Administration (CMA) for the period of 1981-2018. Rainfall totals during AprilJune (AMJ) at 14 uniformly spread stations in Guangdong, Guangxi, and Fujian, as well as their average, were forecasted in this study. Reanalysis data were obtained from the ECMWF interim reanalysis (ERA-Interim) dataset on a $2.5^{\circ} \times 2.5^{\circ}$ grid provided by the European Centre for Medium-Range Weather Forecast (ECMWF). The climate variables used include the surface air temperature $(\mathrm{SAT}), 850-\mathrm{hPa}$ zonal wind $\left(U_{850}\right), 850-\mathrm{hPa}$ meridional wind $\left(V_{850}\right), 850-\mathrm{hPa}$ relative humidity $\left(\mathrm{RH}_{850}\right)$, 850-hPa geopotential height $\left(H_{850}\right)$ and 500-hPa geopotential height $\left(H_{500}\right)$. 
TABLE 1. Detail information of ENSO events over 1982-2018.

\begin{tabular}{|c|c|c|c|c|c|}
\hline & Event year & Length & The strongest month & Strength & Type \\
\hline \multirow[t]{12}{*}{ El Niño } & $1982 / 83$ & 15 & Jan 1983 & Strong & EP \\
\hline & $1986 / 87$ & 10 & Dec 1986 & Moderate & EP \\
\hline & $1987 / 88$ & 8 & Sep 1987 & Strong & EP \\
\hline & $1991 / 92$ & 14 & Jan 1992 & Strong & EP \\
\hline & $1994 / 95$ & 7 & Dec 1994 & Moderate & $\mathrm{CP}$ \\
\hline & $1997 / 98$ & 13 & Nov 1997 & Strong & EP \\
\hline & $2002 / 03$ & 9 & Nov 2002 & Moderate & $\mathrm{CP}$ \\
\hline & $2004 / 05$ & 8 & Sep 2004 & Weak & $\mathrm{CP}$ \\
\hline & $2006 / 07$ & 5 & Dec 2006 & Weak & EP \\
\hline & $2009 / 10$ & 9 & Dec 2009 & Moderate & $\mathrm{CP}$ \\
\hline & $2014 / 15$ & 8 & Jun 2015 & Weak & $\mathrm{EP}$ \\
\hline & $2015 / 16$ & 11 & Jan 2016 & Strong & $\mathrm{EP}$ \\
\hline \multirow[t]{14}{*}{ La Niña } & $1983 / 84$ & 5 & Nov 1983 & Weak & $\mathrm{CP}$ \\
\hline & $1984 / 85$ & 11 & Dec 1984 & Weak & $\mathrm{EP}$ \\
\hline & $1988 / 89$ & 13 & Dec 1988 & Strong & $\mathrm{EP}$ \\
\hline & $1995 / 96$ & 8 & Nov 1995 & Moderate & EP \\
\hline & $1998 / 99$ & 12 & Jan 1999 & Strong & $\mathrm{CP}$ \\
\hline & $1999 / 00$ & 12 & Jan 2000 & Strong & $\mathrm{EP}$ \\
\hline & $2000 / 01$ & 8 & Dec 2000 & Weak & $\mathrm{CP}$ \\
\hline & $2005 / 06$ & 5 & Jan 2006 & Weak & $\mathrm{EP}$ \\
\hline & $2007 / 08$ & 12 & Jan 2008 & Strong & $\mathrm{EP}$ \\
\hline & $2008 / 09$ & 5 & Jan 2009 & Weak & $\mathrm{CP}$ \\
\hline & $2010 / 11$ & 12 & Oct 2010 & Strong & EP \\
\hline & $2011 / 12$ & 9 & Nov 2011 & Moderate & $\mathrm{CP}$ \\
\hline & $2016 / 17$ & 5 & Oct 2016 & Weak & $\mathrm{EP}$ \\
\hline & $2017 / 18$ & 6 & Jan 2018 & Weak & $\mathrm{EP}$ \\
\hline
\end{tabular}

The dynamic model used in this study was the NCEP Climate Forecast System, version 2 (CFSv2; Saha et al. 2014). The model data cover a common $37-y r$ period of 1982-2018 derived from retrospective forecasts and operational forecasts. For CFSv2, a seasonal forecast starting at the beginning of April is employed, and only its ensemble mean was used here. To be consistent with the ERA-Interim reanalysis dataset, model outputs were interpolated onto a $2.5^{\circ} \times 2.5^{\circ}$ grid using the bilinear interpolation method.

According to the definition at National Oceanic and Atmospheric Administration/Climate Prediction Center, the running 3-month mean sea surface temperature anomaly (SSTA) over the Niño-3.4 region $\left(5^{\circ} \mathrm{S}-5^{\circ} \mathrm{N}, 120^{\circ}-170^{\circ} \mathrm{W}\right)$ was used to identify El Niño (warm) and La Niña (cold) events. If Niño-3.4 SSTA $\geq$ $0.5^{\circ} \mathrm{C}\left(\leq-0.5^{\circ} \mathrm{C}\right)$ for at least 5 consecutive months, it is defined as an El Niño (La Niña) event. And the El Niño/La Niña were classified according to their intensities into weak (absolute SSTA $<1.0^{\circ} \mathrm{C}$ ), moderate $\left(1.0^{\circ} \mathrm{C} \leq\right.$ absolute SSTA $<1.5^{\circ} \mathrm{C}$ ), and strong (absolute SSTA $\geq 1.5^{\circ} \mathrm{C}$ ) events following Jan Null (https:// ggweather.com/enso/oni.htm). The Niño-3 and Niño-4 SST indices obtained from the Tokyo Climate Center of the Japan Meteorological Agency were used to calculate the eastern Pacific (EP-type) and central Pacific (CP-type) ENSO index according to Ren et al. (2018).
The detail of El Niño/La Niña events over 1982-2018 was shown in Table 1.

\section{Methods}

To develop a statistical downscaling model for early summer rainfall at 14 stations in South China, SAT, $H_{500}, H_{850}, U_{850}, V_{850}$, and $\mathrm{RH}_{850}$ were used. Each variable and the combinations of variables were potential predictors. For the predictor domain, an area covering as much South China as possible was used as potential domain. The whole data period (1981-2018) was divided into two parts with the first 30 years (1981-2010) as the training period to build the model and the following 8 years (2011-18) as the independent testing period to validate the model. To determine the predictor variables and the domain, different downscaling models with different variables and domains were built and tested based on leave-five-out cross validation during the training period, and the better-performing model was finally selected. To measure the model's agreement with observations, six statistical metrics were employed; these were temporal correlation coefficient (TCC), relative error (RE), root-mean-square error (RMSE), hit rate (HIT: the ratio of years in which the anomaly sign was correctly forecasted to the total number of years), interannual variability ratio $\left(R_{\mathrm{iv}}\right.$ : the ratio of the 

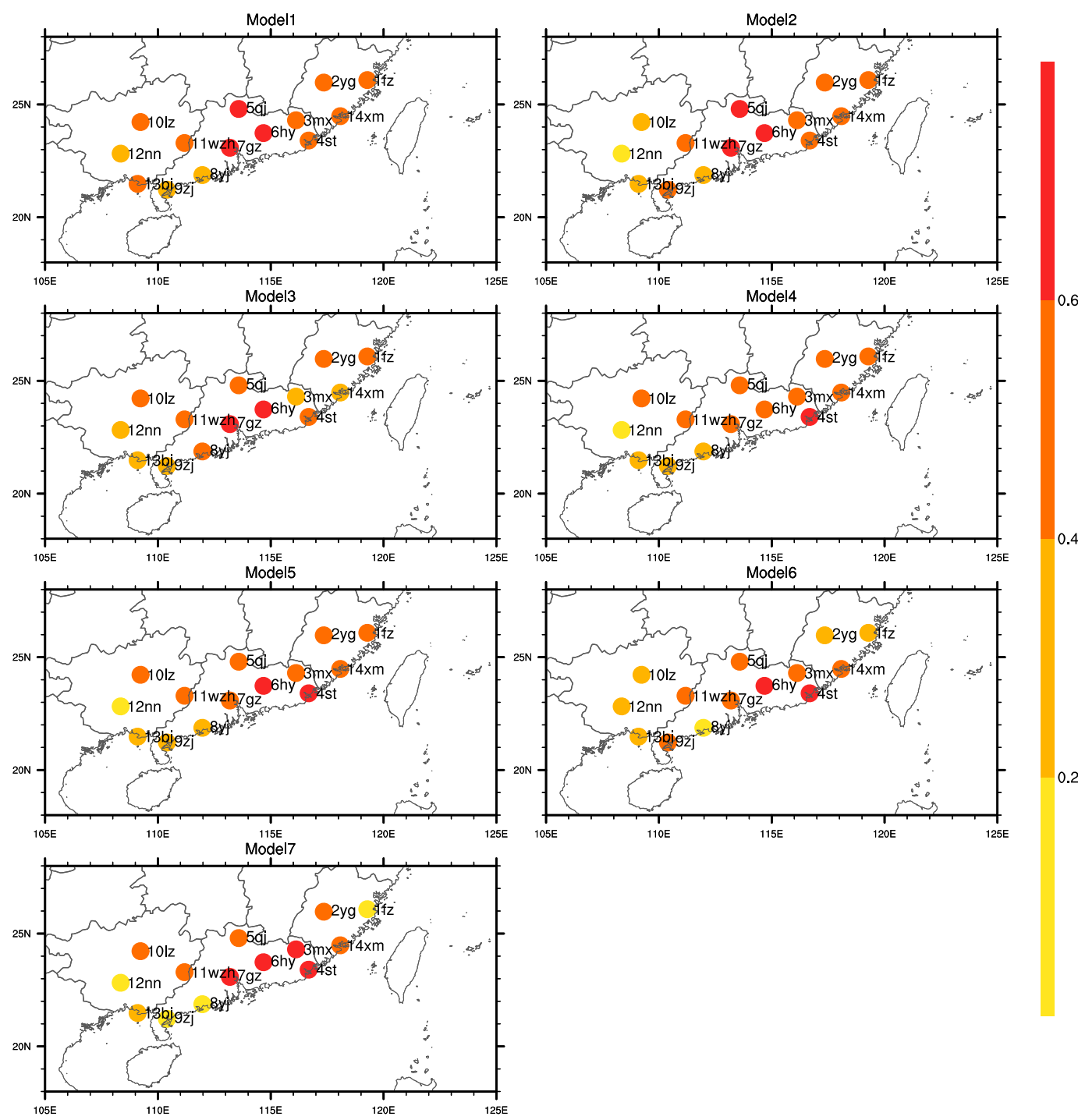

FIG. 1. The distribution of temporal correlation coefficients (TCCs) at 14 stations in South China between the observed and statistical downscaled rainfall via cross validation from 7 better-performing statistical downscaling models over the training period (1981-2010).

forecasted interannual standard deviation to the observed interannual standard deviation), and NashSutcliffe efficiency (NSE). NSE was a normalized statistic that determined the relative magnitude of the residual variance ("noise") compared to the measured data variance ("information"); the value of NSE is $\leq 1$, and NSE $=1$ is the optimal value (Nash and Sutcliffe 1970; Pease et al. 2017; Mehan et al. 2019). And it was calculated as follows:

$$
\mathrm{NSE}=1-\left[\frac{\sum_{i=1}^{n}\left(Y_{i}^{\mathrm{obs}}-Y_{i}^{\mathrm{sim}}\right)^{2}}{\sum_{i=1}^{n}\left(Y_{i}^{\mathrm{obs}}-Y^{\mathrm{mean}}\right)^{2}}\right],
$$

where $Y_{i}^{\text {obs }}$ was the $i$ th observation, $Y_{i}^{\text {sim }}$ was the $i$ th simulated value, $Y^{\text {mean }}$ was the mean of observation, and $n$ was the number for years.

The TCC is the statistic of standard regression, and it describes the degree of collinearity between forecast and observation data. The RMSE and HIT are the statistics of error index. And the NSE is the dimensionless statistic. They can evaluate the performance of the models from different angles.

This study employed the BP-CCA method to build the statistical downscaling model. It primarily includes two procedures: EOF analysis and CCA. Details can be found in the study by Jia et al. (2010). In the progress of EOF analysis, we reduce the dimensions of the $X$ field 
(predictors) and $Y$ field (station rainfall). It is worth noting that the optimal amount of PCs retained after EOF analysis is determined by the performance in cross validation during the training period. In addition, the pairs of CCA modes that are significantly correlated with each other (at the 0.05 level) are retained to build the final regression equation.

\section{Results}

\section{a. Statistical downscaling model establishment and validation}

Using the BP-CCA method, a number of statistical downscaling models were built with different predictor variables and domains. The model performance was evaluated based on leave-five-out cross validation during the training period (1981-2010). The top seven models' performances measured by TCCs at 14 stations are shown in Fig. 1. These seven models generally performed well in forecasting station rainfall. Even for the seventh model, the average TCC at 14 stations is 0.43 ; and the TCCs at 9 out of 14 stations are significant at the 0.05 level. Detailed information about the top seven models and their performances for both station rainfall and regional average rainfall are summarized in Table 2. The top seven models were built with $U_{850}+\mathrm{RH}_{850}, U_{850}+\mathrm{RH}_{850}+\mathrm{SAT}, V_{850}$, $V_{850}+\mathrm{RH}_{850}, V_{850}+\mathrm{RH}_{850}+\mathrm{SAT}, U_{850}$, and $H_{850}+$ $H_{500}$, respectively. They all produce good forecasts as assessed through cross validation. For station rainfall, the lowest average TCC is 0.43 , the lowest average HIT is $67 \%$, the highest average RMSE is $29 \%$, and the smallest average NSE is 0.16 . For regional average rainfall, the lowest TCC is 0.66 , the lowest HIT is $73 \%$, the highest average RMSE is $14 \%$, and the smallest NSE is 0.39 . The first model performed best; thus, it was chosen as the downscaling model here. Its details are provided in the following section.

Figure 2 shows the distribution of correlation coefficient of the first pair of BP-CCA PCs from Model 1 with the ERA 850-hPa horizontal winds and humidity anomalies as well as the observational rainfall anomalies at 14 stations. Corresponding to the anomalous southwesterly from the northern South China Sea (SCS), water vapor is transferred to South China. The anomalous northeasterly from the Yangtze River area hinders the farther northward transfer of water vapor, resulting in anomalous wet conditions at the southern coast. Moreover, the anomalous southwesterly and northeasterly meet in South China, leading to local convergence and ascent. The above situation gives rise to consistently sufficient rainfall at the

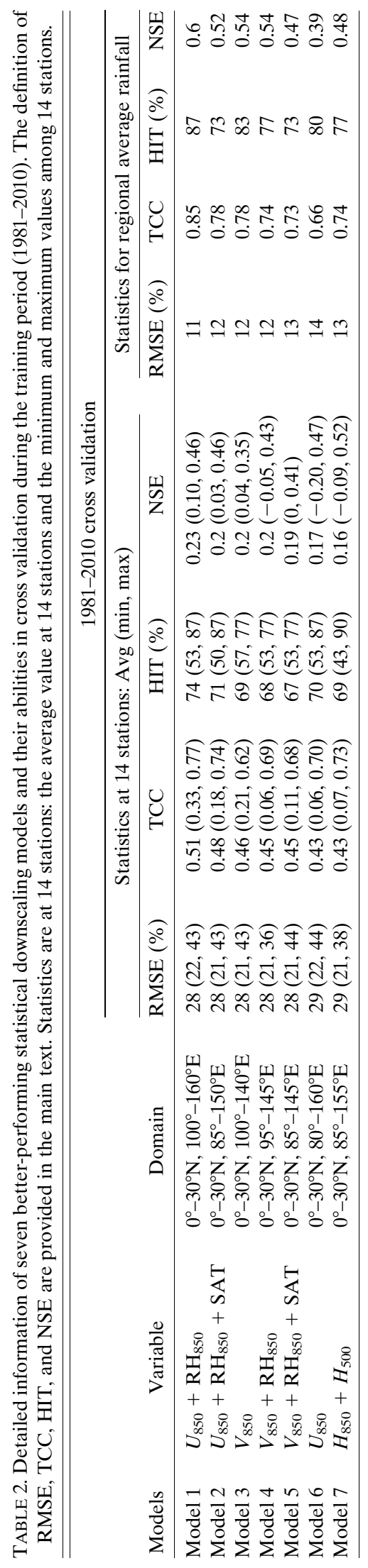


(a)

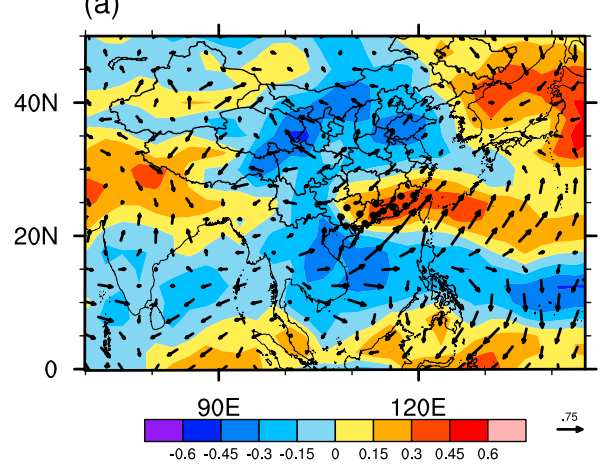

(b)

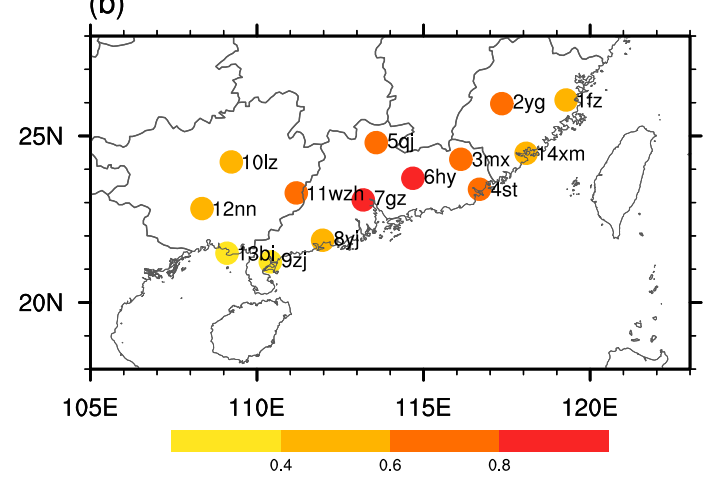

FIG. 2. The distribution of correlation coefficients of the first pair of BP-CCA PCs from Model 1 with (a) the zonal wind, meridional wind, and humidity at $850 \mathrm{hPa}$ (the black dots note the 14 stations in SC) and (b) the observational early summer rainfall at 14 stations.

14 stations, especially at the stations in middle and eastern South China.

The downscaling model was fitted with this pair of BP-CCA models and the downscaled rainfall for the 14 stations were produced. The TCCs of the downscaled rainfall against observations at 14 stations are shown in Fig. 3a. The average TCC at 14 stations was 0.58 , and the TCCs at 13 out of 14 stations (all except Zhanjiang station) are significant at the 0.05 level. In addition to station rainfall, the South China regional average rainfall is also well represented. Figure 4 compares the downscaled regional average rainfall with the observed rainfall. There is good agreement between the observed and downscaled rainfall, with a TCC of 0.96 , an RMSE of $11 \%$, an HIT of $90 \%$, and a NSE of 0.64 for $1981-2010$.

To validate the downscaling model, an independent test from 2011 to 2018 was performed. The TCCs between observed and downscaled station rainfall are shown in Fig. 3b. The average TCC at 14 stations is 0.52 , and TCCs at 8 stations are significant at the 0.05 level. The TCCs at the Yangjiang, Qujiang, and
Nanning stations are relatively low. The downscaled $\mathrm{SC}$ average rainfall over the testing period is shown in Fig. 4. It maintains the good performance as it does in the training period, with a TCC of 0.94 , an RMSE of $6 \%$, a HIT of $88 \%$, and an NSE of -0.13 .

\section{b. Application of the statistical downscaling model to produce seasonal forecast}

To produce practical seasonal forecast, our statistical downscaling model was applied to dynamic model outputs (i.e., CFSv2). The CFSv2 outputs were first standardized by their own long-term means and standard deviations and then projected to the downscaling model to obtain the rainfall forecast at 14 stations. The forecasts obtained from directly CFSv2 and the statistical downscaling model were compared to see whether the forecasts for station rainfall were improved through statistical downscaling.

Figure 5 shows the TCCs and the RMSEs at 14 stations over 1982-2018 derived from the downscaling model and the CFSv2 and their difference. The TCCs at 11 out of 14 stations increased, especially in western

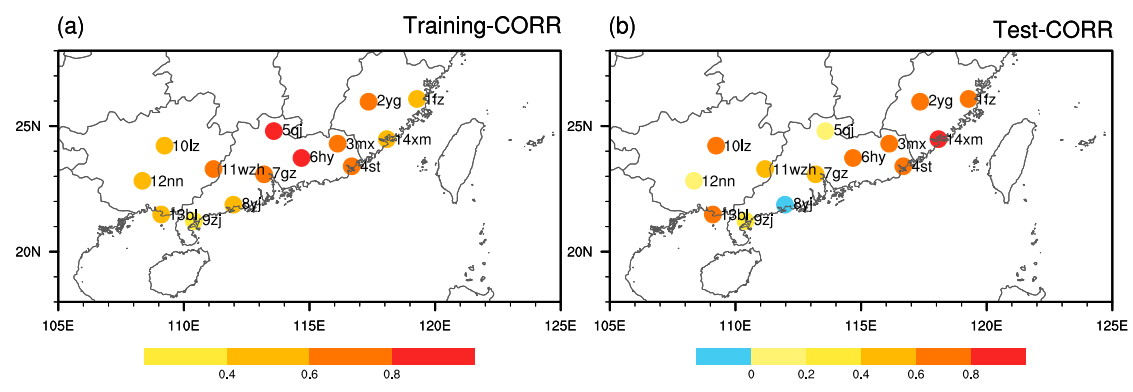

FIG. 3. The distribution of temporal correlation coefficients at 14 stations in South China between the observed and statistical downscaled rainfall over (a) the training period (1981-2010) and (b) the independent testing period (2011-18). 


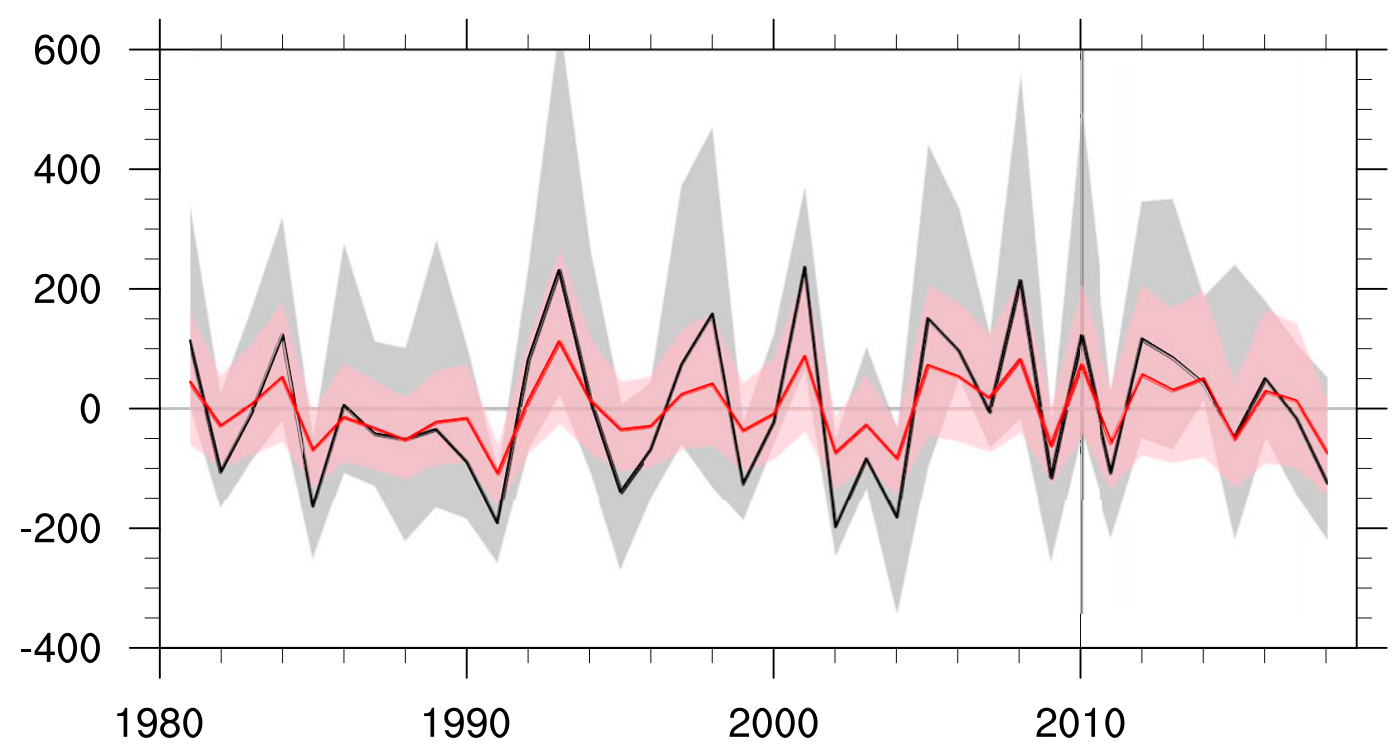

FIG. 4. South China regional average rainfall anomaly (solid line) and the 25th-75th percentiles among rainfall anomalies at 14 stations (shaded band) from observations (black) and the statistical downscaling model (red) over the training period (1981-2010) and the independent test period (2011-18).

South China. The average TCC increased from 0.14 to 0.31 , and the stations with significant TCCs $(0.05$ level $)$ increased from 2 to 6 . Compared with that of CFSv2, the RMSEs decreased at most (12 out of 14) stations after being downscaled, and the average RMSE decreased from $30 \%$ to $29 \%$. All results indicate that the forecasts of station rainfall in South China are remarkably improved by the statistical downscaling model.

Whether the forecasts for regional average rainfall were improved through statistical downscaling was also examined. Figure 6 compares the regional average rainfall from CFSv2 and downscaling model. The downscaled rainfall is obviously closer to the observations than the original CFSv2 forecast, with increased TCCs, reduced RMSEs and obviously enhanced interannual variability. The TCC increases from 0.11 to 0.53 , the RMSE decreases from $17 \%$ to $14 \%$, and the $R_{\mathrm{iv}}$ reaches 0.41 , closer to 1 than the original 0.18 .

As we know that ENSO is the strongest signal in the interannual variation of ocean-atmosphere system, and it has huge impacts on global climate. Previous studies indicated that decaying ENSO exerts crucial effect on early summer rainfall anomaly in South China (Wu and Yao 2018). It is necessary to examine the dependence of forecast skills on ENSO. According to El Niño/La Niña events identified in Table 1, we performed a composition of forecast skills for regional average rainfall, measured with relative error, based on El Niño, La Niña, and normal years. Table 3 shows the relative errors from both CFSv2 and downscaling model in the El Niño, La Niña, and normal years. In El Niño years, the average relative errors are $78.75 \%$ and $68.69 \%$, respectively, for CFSv2 and downscaling model. In La Niña years, the average relative errors are $108.01 \%$ and $91.90 \%$. In normal years, the average relative errors are $107.56 \%$ and $85.81 \%$, respectively. Forecast error is reduced when it follows an El Niño event in comparison with a La Niña or normal year in both CFSv2 and the downscaling model, but these reductions are not statistically significant.

We take into account the strength of ENSO that might affect the results. All ENSO events were classified into weak, moderate, and strong events, according to their intensities. We take moderate events and above as the "real" ENSO to do the composition. In the moderate and above El Niño years, the average relative errors are $72.47 \%$ and $57.91 \%$ for CFSv 2 and downscaling model, respectively. In the moderate and above La Niña years, the average relative errors are $83.71 \%$ and $72.40 \%$, respectively. In normal years, the average relative errors are $114.39 \%$ and $96.51 \%$, respectively. Forecast error is clearly reduced when it follows the moderate and above El Niño or La Niña years in comparison with normal year in both CFSv2 and downscaling model; however, the reduction is only statistically significant (at the 0.1 level) when it follows the moderate and above El Niño event in the downscaling model. Besides, we considered only the strong ENSO events, and obtained the same results.

In addition, we also considered that the type of ENSO might affect the results. ENSO events were classified 


\section{TCC}

(a) DS

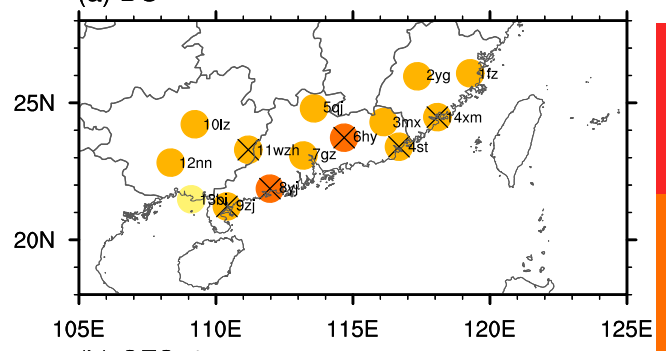

(b) CFSv2
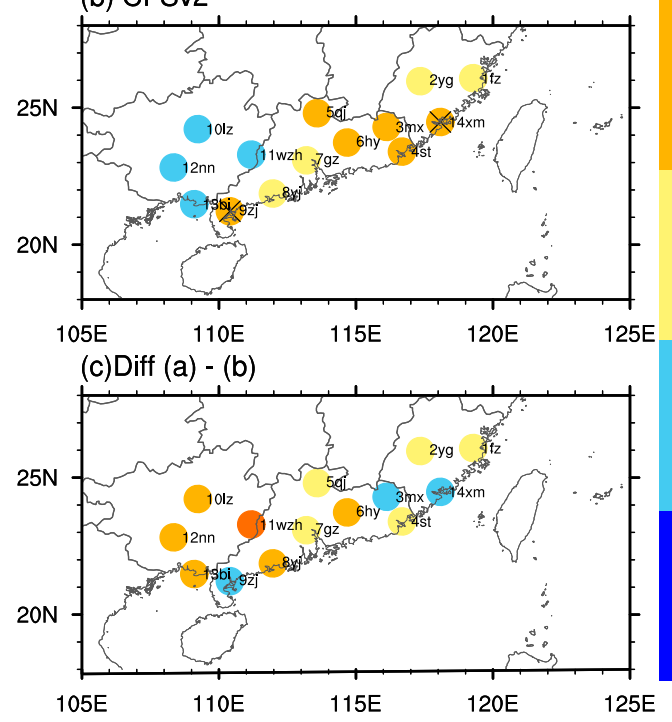

(d) DS

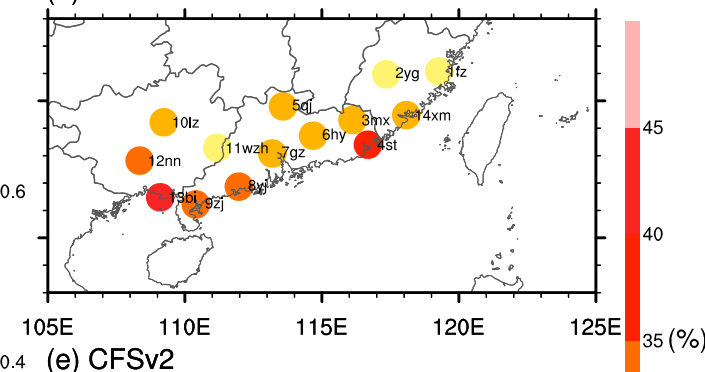

0.4 (e) CFSv2

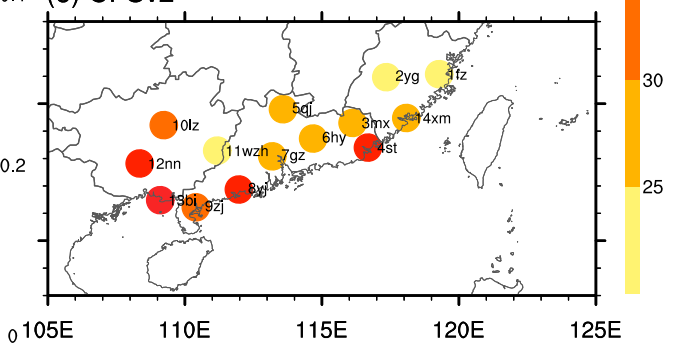

0105E $\quad 110 E$
(f) $\operatorname{Diff}(d)-(e)$

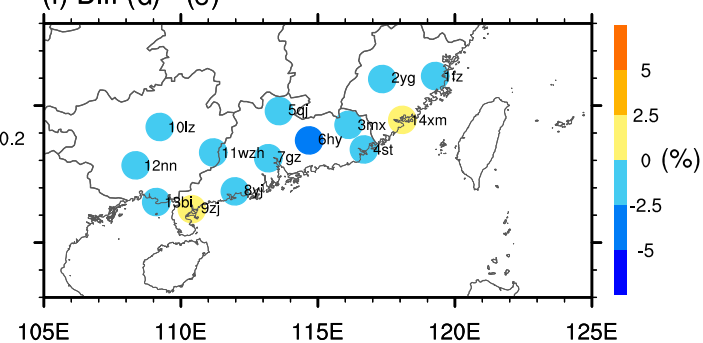

FIG. 5. The distribution of temporal correlation coefficients at 14 stations in South China between the observed and forecasted rainfall from the (a) statistical downscaling model and (b) CFSv2 over 1982-2018. (c) The difference between (a) and (b). The marker $\times$ indicates that the temporal correlation coefficient is significant at the 0.05 level. (d)-(f) As in (a)-(c), but for the RMSE.

into EP-ENSO events and CP-ENSO events. In EP-type El Niño years, the average relative errors are $51.79 \%$ and $44.34 \%$ for CFSv2 and the downscaling model, respectively. In CP-type El Niño years, the average relative errors are $132.67 \%$ and $117.39 \%$. And in EP-type La Niña years, the average relative errors are $96.26 \%$ and $87.05 \%$. In CP-type La Niña years, the average relative errors are $129.17 \%$ and $100.62 \%$. Forecast error is clearly reduced when it follows EP-type El Niño years in both CFSv2 and downscaling model, and the reductions are statistically significant at the 0.1 level. In summary, the EP-type ENSO events had a greater impact on the forecast skill of South China early summer rainfall than the CP-type ENSO events.

\section{Summary and discussion}

Based on the relationship between station rainfall in South China and large-scale low-level circulation and humidity conditions, a statistical downscaling model for South China early summer rainfall was developed using the BP-CCA method. Based on the cross-validated performance during the training period (1981-2010), the best statistical downscaling model was determined and was validated using the independent dataset from 2011 to 2018. Then, the statistical downscaling model was applied to the CFSv2 outputs to produce seasonal forecasts of South China early summer rainfall. The main results can be summarized as follows.

This statistical downscaling model was built with $U_{850}$ and $\mathrm{RH}_{850}$ within a domain of $0^{\circ}-30^{\circ} \mathrm{N}, 100^{\circ}-160^{\circ} \mathrm{E}$. Anomalous southwesterly winds that carry sufficient water vapor encounter anomalous northeasterly winds from the Yangtze River, resulting in a wet anomaly in South China. This downscaling model provided good agreement with observations in both the training and independent test periods. In the training period, for station rainfall, the average TCC at 14 stations was 


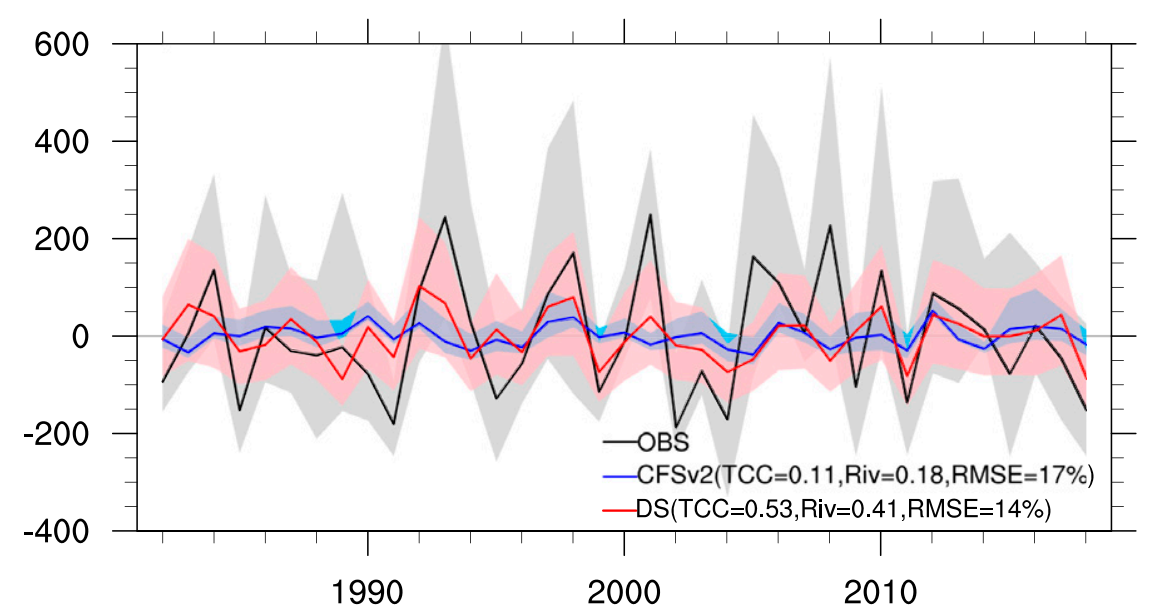

FIG. 6. South China regional average rainfall anomaly (solid line) and the 25 th -75 th percentiles among rainfall anomalies at 14 stations (shade band) from observations (black), the CFSv2 forecast (blue), and the statistical downscaling model forecast (red) over 1982-2018. Definitions of RMSE, $R_{\mathrm{iv}}$, and TCC are provided in the main text, and they are calculated based on the regional average rainfall anomaly.

0.51 , the average RMSE was $28 \%$, the average HIT was $74 \%$, and the average NSE was 0.23 ; for regional average rainfall, the TCC was 0.85 , the RMSE was $11 \%$, the HIT was $87 \%$, and the NSE was 0.6 . In the independent test period, for station rainfall, the average TCC at 14 stations was 0.52 , the average RMSE was $21 \%$, the average HIT was $71 \%$, and the NSE was 0.03; for regional average rainfall, the TCC was 0.94 , the RMSE was $6 \%$, the HIT was $88 \%$, and the NSE was -0.13 .

The statistical downscaling model was applied to the CFSv2 outputs to produce seasonal forecasts of rainfall at 14 stations for 1982-2018. Compared with the original CFSv2 forecast, the forecasts for both station rainfall and regional average rainfall are remarkably improved after statistical downscaling. At the station scale, 11 out of 14 stations had increased TCC. The average TCC at 14 stations increased from 0.14 to 0.31 . At the regional scale, after statistical downscaling, the TCC increased from 0.11 to 0.53 , and the $R_{\mathrm{iv}}$ increased from 0.18 to 0.41 . All results indicated that our statistical downscaling model is able to forecast station rainfall and regional average rainfall in South China better than the CFSv2.

Dependence of forecast skills for the regional average rainfall on the phase of ENSO was examined. Forecast error is clearly reduced when it follows an El Niño event in comparison with a La Niña or normal event in both the CFSv2 and downscaling model, but this reduction is not statistically significant. Whether the ENSO intensity could affect above result was further examined. Significantly reduced forecast error (at the 0.1 level) could be seen in our downscaling model, but not in CFSv2, only when it followed moderate El Niño and above. Furthermore, the effect of type on ENSO events was also examined. The reductions of forecast error were both statistically significant at the 0.1 level in CFSv2 and downscaling model when it followed an EP-type El Niño event.

Our study reveals that the forecast for South China station rainfall from CFSv2 can be improved by using a statistical downscaling model. The average TCC over 14 stations increased from 0.14 to 0.31 for $1982-2018$, and the stations with significant TCCs ( 0.05 level) increased from 2 to 6. Jia et al. (2010) also utilized the BP-CCA method to calibrate a statistical downscaling model and produced forecasts of winter rainfall at 160 stations over China with outputs from CGCM/NCC. Compared with this work, larger improvement for station rainfall forecasts is found via statistical downscaling in our work. Generally, our results are exciting and have the potential to be employed in real-time operational forecasts.

The CFSv2 forecast in this study began at the beginning of April, which produced a 0-month-lead forecast for early summer rainfall. In operational rainfall forecasting, forecasts with longer lead time are needed. We have tried to apply our downscaling model to CFSv2 forecasts with longer lead time, but we did not obtain satisfactory forecasts. This failure is mainly due to the deficiency of CFSv2 in forecasting the $U_{850}$ and $\mathrm{RH}_{850}$. Thus, further research is needed to improve the CFSv2 lead forecast of the circulation and humidity fields and subsequently to improve the lead forecasts of station rainfall. 
TABLE 3. The relative error of the regional average rainfall in South China (SC) forecasted by CFSv2 and the downscaling model (DS).

\begin{tabular}{|c|c|c|c|c|c|}
\hline & \multirow[b]{2}{*}{ Strength } & \multirow[b]{2}{*}{ Type } & \multirow[b]{2}{*}{ Year } & \multicolumn{2}{|c|}{$\begin{array}{l}\text { Relative } \\
\text { error }(\%)\end{array}$} \\
\hline & & & & CFSv2 & DS \\
\hline \multirow[t]{16}{*}{ El Niño } & \multirow[t]{5}{*}{ Strong } & EP & 1983 & 38.49 & 59.42 \\
\hline & & EP & 1988 & 35.72 & 27.44 \\
\hline & & EP & 1992 & 67.77 & 8.57 \\
\hline & & EP & 1998 & 133.02 & 91.35 \\
\hline & & $\mathrm{EP}$ & 2016 & 1.95 & 10.56 \\
\hline & \multirow[t]{4}{*}{ Moderate } & EP & 1987 & 45.66 & 65.25 \\
\hline & & $\mathrm{CP}$ & 1995 & 120.24 & 141.34 \\
\hline & & $\mathrm{CP}$ & 2003 & 77.38 & 43.74 \\
\hline & & $\mathrm{CP}$ & 2010 & 132.03 & 73.55 \\
\hline & \multirow[t]{3}{*}{ Weak } & $\mathrm{CP}$ & 2005 & 201.03 & 210.94 \\
\hline & & EP & 2007 & 0.2 & 15.16 \\
\hline & & EP & 2015 & 91.51 & 76.97 \\
\hline & Avg of EP & & & 51.79 & 44.34 \\
\hline & Avg of CP & & & 132.67 & 117.39 \\
\hline & $\begin{array}{l}\text { Avg of strong }+ \\
\text { moderate }\end{array}$ & & & 72.47 & 57.91 \\
\hline & Avg of all events & & & 78.75 & 68.69 \\
\hline \multirow[t]{18}{*}{ La Niña } & \multirow[t]{5}{*}{ Strong } & EP & 1989 & 27.47 & 65.82 \\
\hline & & $\mathrm{CP}$ & 1999 & 111.45 & 40.13 \\
\hline & & EP & 2000 & 16.96 & 1.37 \\
\hline & & EP & 2008 & 254.13 & 277.54 \\
\hline & & EP & 2011 & 106.49 & 54.32 \\
\hline & \multirow[t]{2}{*}{ Moderate } & EP & 1996 & 33.05 & 22.88 \\
\hline & & $\mathrm{CP}$ & 2012 & 36.39 & 44.78 \\
\hline & \multirow[t]{7}{*}{ Weak } & $\mathrm{CP}$ & 1984 & 130.9 & 95.33 \\
\hline & & EP & 1985 & 151.58 & 120.64 \\
\hline & & $\mathrm{CP}$ & 2001 & 266.94 & 209.11 \\
\hline & & EP & 2006 & 81.85 & 87.83 \\
\hline & & $\mathrm{CP}$ & 2009 & 100.17 & 113,74 \\
\hline & & EP & 2017 & 59.56 & 88.32 \\
\hline & & EP & 2018 & 135.2 & 64.76 \\
\hline & Avg of EP & & & 96.26 & 87.05 \\
\hline & Avg of CP & & & 129.17 & 100.62 \\
\hline & $\begin{array}{l}\text { Avg of strong }+ \\
\text { moderate }\end{array}$ & & & 83.71 & 72.40 \\
\hline & Avg of all events & & & 108.01 & 91.90 \\
\hline \multirow[t]{12}{*}{ Normal year } & & & 1982 & 87.17 & 87.17 \\
\hline & & & 1986 & 0.99 & 35.76 \\
\hline & & & 1990 & 117.78 & 95.85 \\
\hline & & & 1991 & 173.43 & 136.82 \\
\hline & & & 1993 & 255.52 & 176.49 \\
\hline & & & 1994 & 58.71 & 74.96 \\
\hline & & & 1997 & 57.41 & 26.17 \\
\hline & & & 2002 & 184.82 & 167.69 \\
\hline & & & 2004 & 143.53 & 97.20 \\
\hline & & & 2013 & 63.68 & 31.21 \\
\hline & & & 2014 & 40.12 & 14.61 \\
\hline & Avg of all events & & & 107.56 & 85.81 \\
\hline
\end{tabular}

Acknowledgments. We thank the three anonymous reviewers for their helpful comments and suggestions. And this study is jointly supported by the National Program on Global Change and Air-Sea Interaction (GASI-IPOVAI-03), the NSFC Project (41975078), and the Key Special Project for Introduced Talents Team of Southern Marine Science and Engineering Guangdong Laboratory (GML2019ZD0601).

\section{REFERENCES}

Barnett, T. P., and R. Preisendorfer, 1987: Origins and levels of monthly and seasonal forecast skill for United States surface air temperatures determined by canonical correlation analysis. Mon. Wea. Rev., 115, 1825-1850, https://doi.org/10.1175/15200493(1987)115<1825:OALOMA > 2.0.CO;2.

Benestad, R. E., 2004: Empirical-statistical downscaling in climate modeling. Eos, Trans. Amer. Geophys. Union, 85, 417-422, https://doi.org/10.1029/2004EO420002.

Chang, Y., J. H. He, Y. Y. Liu, and P. Liang, 2006: Features of moisture transport of in pre-summer flood season of drought and flood years over South China. Plateau Meteor., 25, 1064 1070.

Chen, P., Z. Jiang, and D. Peng, 2017: Multi-model statistical downscaling of spring precipitation simulation and projection in central Asia based on canonical correlation analysis. Acta Meteor. Sin., 75, 236-247.

Chi, Y. Z., J. H. He, and Z. W. Wu, 2005: Features analysis of the different precipitation periods in the pre-flood season in South China. J. Nanjing Inst. Meteor., 28, 163-171.

Deng, L., and Q. Wang, 2002: On the relationship between precipitation anomalies in the first raining season (April-June) in southern China and SST over offshore waters in China. J. Trop. Meteor., 18, 45-55.

Ding, W. Y., and J. P. Liang, 2002: Relationship between the variations of OLR over South China sea and the precipitation in rainy seasons in South China. J. Trop. Meteor., 18, 276-282.

Fowler, H. J., S. Blenkinsop, and C. Tebaldi, 2007: Linking climate change modelling to impacts studies: Recent advances in downscaling techniques for hydrological modelling. Int. J. Climatol., 27, 1547-1578, https://doi.org/10.1002/joc.1556.

Gong, D., and S. Wang, 1999: Response of global subtropical highs to the equatorial eastern Pacific SST anomaly. Acta Oceanol. Sin., 18, 203-214.

Guo, Y., J. Li, and Y. Li,2014: Seasonal forecasting of North China summer rainfall using a statistical downscaling model. J. Appl. Meteor. Climatol., 53, 1739-1749, https://doi.org/ 10.1175/JAMC-D-13-0207.1.

Hu, Y., Y. Rong, J. Wei, C. Li, H. Tang, and S. Li, 2017: Relationship between pre-flood season precipitation in South China and Indian Ocean SST at earlier stages. Water Resour. Prot., 33, 106-116.

Hui, M., W. Qianqian, and C. Zhenhua, 2006: Spatial and temporal variations in pre-summer flood period precipitation of South China. Plateau Meteor., 25, 325-329.

- C. Zhen-Hua, J. Li-Ping, W. Qian-Qian, and L. I. N. Ze-Jin, 2009: SVD analysis between the annually first raining period precipitation in the south of China and the SST over offshore waters in China. J. Trop. Meteor., 25, 241-245.

Jia, X., L. Chen, W. Li, and D. Chen, 2010: Statistical downscaling based on BP-CCA: Predictability and application to the winter temperature and precipitation in China. Acta Meteor. Sin., 68, 398-410.

Kanamitsu, M., and Coauthors, 2002: NCEP dynamical seasonal forecast system 2000. Bull. Amer. Meteor. Soc., 83, 1019-1037, https:// doi.org/10.1175/1520-0477(2002)083<1019:NDSFS > 2.3.CO;2. 
Lee, S. S., J. Y. Lee, K. J. Ha, B. Wang, and J. K. E. Schemm, 2011: Deficiencies and possibilities for long-lead coupled climate prediction of the Western North Pacific-East Asian summer monsoon. Climate Dyn., 36, 1173-1188, https://doi.org/ 10.1007/s00382-010-0832-0.

Liu, Y., and K. Fan, 2014: An application of hybrid downscaling model to forecast summer precipitation at stations in China. Atmos. Res., 143, 17-30, https://doi.org/10.1016/j.atmosres.2014.01.024.

— $-\longrightarrow$, and H.-J. Wang, 2011: Statistical downscaling prediction of summer precipitation in southeastern China. Atmos. Oceanic Sci. Lett., 4, 173-180, https://doi.org/10.1080/16742834.2011.11446925.

_ _ _ , and Y. Zhang, 2013: A statistical downscaling model for summer rainfall over China stations based on the climate forecast system. Chin. J. Atmos. Sci., 37, 1287-1296.

Lu, R., R. Chan-Su, and D. Buwen, 2002: Associations between the western North Pacific monsoon and the South China Sea monsoon. Adv. Atmos. Sci., 19, 12-24, https://doi.org/10.1007/ s00376-002-0030-Z.

Ma, H., Z. H. Chen, W. S. Mao, and Q. Q. Wang, 2009: Analysis of precipitation in the annually first rainy period and general circulation in the South China. J. Trop. Meteor., 25, 89-96.

Mehan, S., R. Aggarwal, M. W. Gitau, D. C. Flanagan, C. W. Wallace, and J. R. Frankenberger, 2019: Assessment of hydrology and nutrient losses in a changing climate in a subsurfacedrained watershed. Sci. Total Environ., 688, 1236-1251, https:// doi.org/10.1016/j.scitotenv.2019.06.314.

Nash, J. E., and J. V. Sutcliffe, 1970: River flow forecasting through conceptual models: Part I. A discussion of principles. J. Hydrol., 10, 282-290, https://doi.org/10.1016/0022-1694(70)90255-6.

Palmer, T. N., and Coauthors, 2004: Development of a European Multimodel Ensemble System for Seasonal to Interannual Prediction (DEMETER). Bull. Amer. Meteor. Soc., 85, 853872, https://doi.org/10.1175/BAMS-85-6-853.
Pease, L. A., N. R. Fausey, J. F. Martin, and L. C. Brown, 2017: Projected climate change effects on subsurface drainage and the performance of controlled drainage in the Western Lake Erie Basin. J. Soil Water Conserv., 72, 240-250, https://doi.org/ 10.2489/jswc.72.3.240.

Ren, H.-L., B. Lu, J. Wan, B. Tian, and P. Zhang, 2018: Identification standard for ENSO events and its application to climate monitoring and prediction in China. J. Meteor. Res., 32, 923-936, https://doi.org/10.1007/s13351-018-8078-6.

Ruan, C., J. Li, and J. Feng, 2015: Statistical downscaling model for late-winter rainfall over Southwest China. Sci. China Earth Sci., 58, 1827-1839, https://doi.org/10.1007/s11430-015-5104-8.

Saha, S., and Coauthors, 2014: The NCEP Climate Forecast System version 2. J. Climate, 27, 2185-2208, https://doi.org/10.1175/ JCLI-D-12-00823.1.

Tung, Y. L., C.-Y. Tam, S.-J. Sohn, and J.-L. Chu, 2013: Improving the seasonal forecast for summertime South China rainfall using statistical downscaling. J. Geophys. Res. Atmos., 118, 5147-5159, https://doi.org/10.1002/JGRD.50367.

Wu, H., and W. Yao, 2018: Possible impacts of El Niño events of different types and intensity on precipitation in the subsequent first rainy season in South China (in Chinese). Chin. J. Atmos. Sci., 42, 1081-1095.

Wu, Z., B. Wang, J. Li, and F. Jin, 2009: An empirical seasonal prediction model of the East Asian summer monsoon using ENSO and NAO. J. Geophys. Res., 114, D18120, https:// doi.org/10.1029/2009JD011733.

Yan, H., Q. Meng, and Y. Li, 2004: The study on CCA and SVD analytical methods. Acta Meteor. Sin., 62, 71-76.

Zheng, B., J. Y. Liang, A. L. Lin, C. H. Li, and D. J. Gu, 2006: Frontal rain and summer monsoon rain during pre-rainy season in South China. Part I: Determination of the division dates. Chin. J. Atmos. Sci., 30, 1207-1216. 